\title{
Synthesis, Characterization and Electrochemical Sensor Based Upon Novel Schiff Base Metal Complexes Derived from the Non-Steroidal Anti-inflammatory Drug, Flufenamic Acid for the Determination of Uric acid and their Biological Applications
}

\author{
Shilpa Kondareddy Gopinath ${ }^{1}$ (i), Malathesh Pari ${ }^{1}$ (i), ArchanaMedehal Rudrannagari ${ }^{1}$ (D), Ishwari \\ Boodihaal Kattebasaveshwara ${ }^{1}$ (i), Shivaprasad Kengunte Halappa 1 ,*(D) \\ 1 Department of Chemistry, Vijayanagara Sri Krishnadevaraya University, Ballari,-583105 Karnataka, India \\ * Correspondence: khsprasad60@gmail.com;
}

Scopus Author ID 57196345185

Received: 21.10.2020; Revised: 28.11.2020; Accepted: 30.11.2020; Published: 11.12.2020

\begin{abstract}
The current trend in coordination chemistry is the design and synthesis of new Schiff base transition metal complexes for therapeutic, diagnostic, and catalytic applications. For decades, it has been observed that special attention is being paid to the chemistry of Schiff base metal complexes because of their wide range of applications. Therefore the present paper involves the synthesis of Schiff base ligand by altering the functional group of the drug, Flufenamic acid. From that Schiff base ligand, four complexes, i.e., $\mathrm{Co}(\mathrm{II}), \mathrm{Cu}(\mathrm{II}), \mathrm{Ni}(\mathrm{II})$, and $\mathrm{Zn}$ (II) have been prepared (SB metal complexes). The synthesized SB metal complexes have been characterized using several spectral and analytical techniques. All the metal complexes show non-electrolytic behavior suggested by molar conductance measurements. Spectral studies suggest that all four metal complexes exhibit octahedral geometry. The modified SB-Co complex/GCE showed a greater electro-catalytic activity and lower potential towards the oxidation of uric acid (UA). The response of UA was linear over the concentration ranging from $\mathrm{CV}$ is $0.5-1.8 \mu \mathrm{mol} / \mathrm{L}$, sensitivity for $131.85 \mu \mathrm{A}^{-1} \mathrm{Mm}^{-2}$, and detection limit for $0.16 \mu \mathrm{M}(\mathrm{S} / \mathrm{N}=3)$. The modified GCE showed very good sensitivity along with good repeatability and reproducibility for the determination of UA. The pure drug, Schiff base ligand, and metal complexes, were also screened for anti-inflammatory and antibacterial activities. The observed results prove that the metal complexes exhibit greater activity than that of the original drug.
\end{abstract}

Keywords: Flufenamic drug; Schiff base ligand;metal complexes; cyclic voltametry; uric acid; antiinflammatory activity; antibacterial activity.

(C) 2020 by the authors. This article is an open-access article distributed under the terms and conditions of the Creative Commons Attribution (CC BY) license (https://creativecommons.org/licenses/by/4.0/).

\section{Introduction}

Owing to the multidimensional applications in the dictum of main branches of science, coordination chemistry is one of the liveliest research fields in chemistry. In bioinorganic chemistry, a leading discipline at the interface of chemistry and biology, there has been a great exploration due to coordination compounds. The reason coordination chemistry has been considerably enriched so rapidly is mainly due to the synthesis and characterization of many Schiff base metal complexes containing sulfur, nitrogen, and oxygen as donor sites. Ligands containing sulfur, nitrogen, and oxygen as donors have been found to be useful as potential 
drugs and show a wide range of interesting biological activities such as antibacterial, antiviral, and antifungal anticonvulsant, anti-inflammatory, antitumor, antimicrobial, anti-mosquito larvae, anti-HIV, etc. Schiff bases are a class of organic compounds containing azomethine ($\mathrm{HC}=\mathrm{N}-$ ) group. Their structure is called an imine compound or alternatively, a Schiff base. It was first prepared by the German chemist Hugo Schiff and, therefore, is referred to as Schiff base. These compounds are prepared by the condensation reaction of carbonyls (aldehydes or ketones) with primary amines accompanied by the elimination of water molecules under specific conditions. Structurally, a Schiff base is a nitrogen analog of an aldehyde or ketone. The carbonyl group $(\mathrm{C}=\mathrm{O})$ has been replaced by an imine or azomethine group [1]. The chelating character of Schiff base towards transition metal ions is very interesting [30]. A Schiff base coordinates with the metal ion through the nitrogen atom of the azomethine group. A functional group with a replaceable hydrogen atom near enough to $>\mathrm{C}=\mathrm{N}$ renders extra stability to metal complexes through chelation. Moreover, due to the smaller size and comparatively higher nuclear charge of transition metals, they have an excellent affinity to form coordination compounds with the Schiff bases. The metal-based chemistry with the biologically active compounds provides an important direction in addressing bacterial, fungal, inflammatory, analgesic, etc., resistance against the use of conventional drugs [28]. Flufenamic acid, 2-[3(trifluoromethyl)phenyl]aminobenzoic acid, is a member of fenamates group, which belongs to a family of non-steroidal anti-inflammatory drugs (NSAIDs). NSAIDs are among the most frequently used medicinal drugs primarily as analgesic, antipyretic and anti-inflammatory agents. These drugs' action is attributable to the inhibition of prostaglandin (PG) synthesis by competitive interaction with the cyclooxygenase-arachidonic acid complex. Flufenamic acid is a non-selective inhibitor of cyclooxygenase (COX), thereby affecting the synthesis of prostaglandins, prostacyclins, and thromboxanes. Two different cyclooxygenases, isoforms, COX-1 and COX-2, have been characterized. Inhibition of the COX-2 system results in antiinflammatory action, while inhibition of the COX-1 enzyme system results in antiinflammatory action as well as gastric irritation. Flufenamic acid is also used to treat musculoskeletal and joint disorders. Although NSAIDs are very widely used, they are well known for causing gastrointestinal ulceration and bleeding [2]. The current coordination chemistry trend is the design and synthesis of new Schiff base transition metal complexes for therapeutic, diagnostic, and catalytic applications. Uric Acid (UA) is produced by xanthine oxidase from xanthine and hypoxanthine, which are, in turn, produced from purine. UA is more toxic to tissues than either hypoxanthine or xanthine. At more concentrations, it may cause diseases such as gout hyperuricemia, and the Lesch-Ny, this is an important determination [3]. The modified electrodes have been reportedly developed for the single detection of AA, DA, or UA by drop coating a bare GCE and a platinum-gold electrode [4,5]. Hence, a simple method can be employed for the determination of UA. In the last few decades, the detection of UA has been carried out using different techniques. Among these methods, CV measurements, particularly those using electrochemical sensors, are most attractive for UA analysis. The reason is that they are simple, rapid, have high sensitivity, and economically labile. These $\mathrm{CV}$ methods have some limitations, such as being time-consuming, complicated sample preparation, etc. In the last decade, nanoparticles ( $\mathrm{Au}, \mathrm{Mn}, \mathrm{Co}$, Ti, etc.), RGO, MWCNTs [6] have been used to chemically modify the electrodes to detect UA using cyclic voltammetry with enhanced sensitivity and selectivity. 


\section{Materials and Methods}

\subsection{General and instrumental.}

All the chemicals and solvents used were of analytical grade. The drug, Flufenamic acid, was purchased from Sri Durga Laboratory Equipment Supplies, Mangalore, Karnataka and was used without any further purification. Distilled ethanol was used as a solvent for synthesis. The metal salts $\mathrm{Cu}^{+2}, \mathrm{Co}^{+2}, \mathrm{Ni}^{+2}$, and $\mathrm{Zn}^{+2}$ acetates were used to synthesize metal complexes. The molar conductance of the synthesized complexes in $1 \times 10^{-3} \mathrm{~mol} \mathrm{dm}^{3} \mathrm{DMF}$ solution was measured using ELICO digital conductivity meter of CM-180 model. The infrared spectra of the ligand and complexes were recorded in $\mathrm{KBr}$ pellets using FTIR Shimadzu spectrometer in the range $4000-400 \mathrm{~cm}^{-1}$. The electronic spectra were recorded using Spectronic 20 UV-Visible spectrophotometer. The ${ }^{1} \mathrm{HNMR}$ spectrum was obtained from IISC, Bangalore. The mass spectrum was recorded on a Micro mass UK PLATFORM II LC-MS Spectrometer. A Bruker D8 advance XRD machine was used for recording the diffraction patterns.

\subsection{Synthesis of Ester (1-(2-[3-(trifluoromethyl)anilino]phenyl)propane-1-one).}

$1 \mathrm{~g}(0.0035 \mathrm{M})$ Flufenamic acid was dissolved in nearly $25 \mathrm{ml}$ ethanol; to this 2 drops of Con. $\mathrm{H}_{2} \mathrm{SO}_{4}$ was added, and the solution was refluxed for about 5 hours. After cooling the solution to room temperature, the preparation was neutralized with sodium carbonate solution ( $1.5 \mathrm{~g}$ dissolved in $25 \mathrm{ml}$ water) and was stirred for 15 more minutes. The separated crude ester was diluted with chloroform. The combined chloroform phases were separated, washed with water, dried over sodium sulfate, and evaporated in a vacuum [7]. The obtained crude ester was recrystallized in ethanol.

\subsection{Synthesis of Carbohydrazide (2-[3-(trifluoromethyl)aniline] benzohydrazide).}

$0.02 \mathrm{M}$ of hydrazine hydrate $(99 \%)$ was added dropwise to the ester $(0.0035 \mathrm{M})$ dissolved in ethanol with constant stirring. Then the solution was heated under reflux for about 15 hours. The solid precipitate obtained in ice-cold water was filtered, dried, and recrystallized with ethanol.

2.4. Synthesis of Schiff base ligand (NI-[(2-hydroxyphenyl)methylidene]-2]3 (trifluoromethyl)aniline]benzohydrazide.

The equimolar ratio of carbohydrazide and salicylaldehyde were separately dissolved in ethanol. They were mixed, and the solution was refluxed for about 5 hours. The yellow solid separated was a Schiff base ligand. It was filtered, dried, and recrystallized in ethanol.

\subsection{Synthesis of metal complexes.}

Ethanolic solutions of the respective metals $\mathrm{CuCl}_{2} .2 \mathrm{H}_{2} \mathrm{O}, \mathrm{CoCl}_{2} .6 \mathrm{H}_{2} \mathrm{O}, \mathrm{NiCl}_{2} \cdot 6 \mathrm{H}_{2} \mathrm{O}$, and anhydrous $\mathrm{ZnCl}_{2}$ were added to an ethanolic solution Schiff base ligand in 1:2 (metal: ligand) molar ratio, and the mixture was heated under reflux for about 3 hours. The colored precipitates obtained were filtered and dried. The scheme of preparation of Schiff base ligand (1) and metal complexes (2) is represented in Figure 1. 


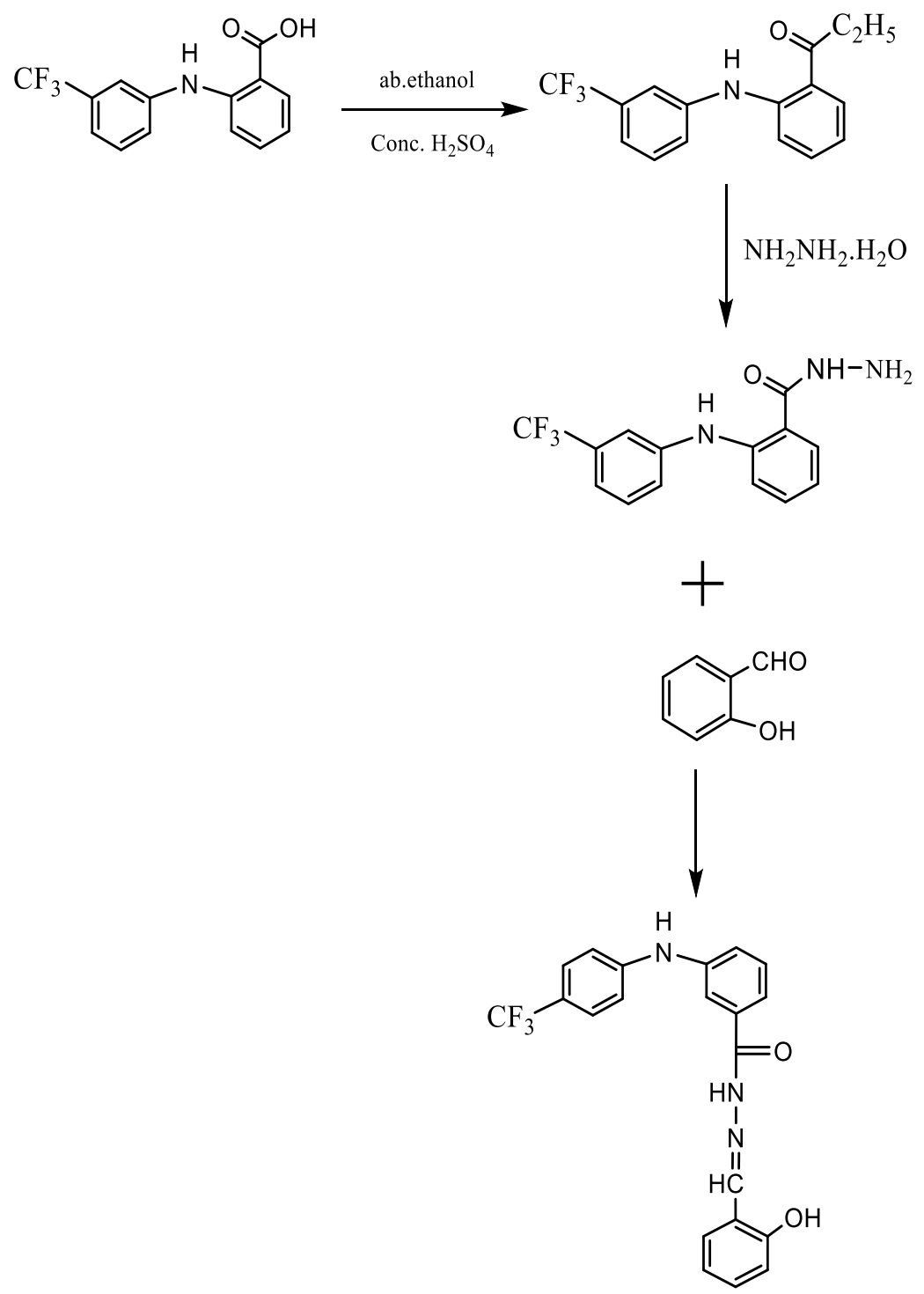

(1) Schiff Base ligand

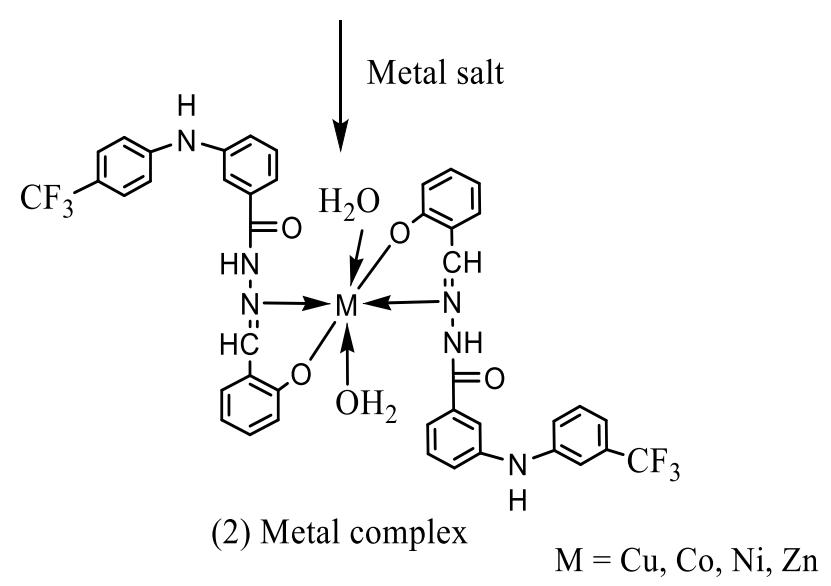

Figure 1. Preparative Scheme of Schiff base ligand (1) and metal complexes (2).

\subsection{Electrode fabrication.}

The GCE was polished with 0.5 and $0.05 \mathrm{~mm}$ alumina slurry on a micro cotton pad and then rinsed with deaerated distilled water. Electrochemical cleaning was done by cycling in the potential range -1.2 to $+1.2 \mathrm{~V}$ for 25 cycles in $0.1 \mathrm{M} \mathrm{H}_{2} \mathrm{SO}_{4}$ at $50 \mathrm{mV} \mathrm{s}^{-1}$. Subsequently, the electrode was washed out with deaerator water and dried by purging $\mathrm{N}_{2}$. 
The complex ink was prepared by dissolving $5 \mathrm{mg}$ of SB-Co (II) complex and $10 \mathrm{~mL}$ $5 \%$ wt of Nafion solution in $0.5 \mathrm{~mL}$ IPA and sonication was done for 15 min to obtain a uniform suspension. The dissolved ink sample of $10 \mathrm{ml}$ was drop cast on a cleaned GCE, and the modified GCE was represented as SB-Co(II)/GCE. The drop cast electrodes were dried in an inert atmosphere and kept in desiccators for later use.

\section{Results and Discussion}

The Elemental analysis data of all the complexes are given in Table 1. The elemental analysis results revealed that all the complexes and ligands have a 1:2 stoichiometry of the type ML2. All the complexes are stable at room temperature, insoluble in common organic solvents. However, they are reasonably soluble in coordinating solvents like DMSO and DMF [8]. The molar conductivity measurements were carried out in DMF solution $\left(1 \times 10^{-3} \mathrm{M}\right)$. The measured conductivity values for the present complexes are too low to account for any dissociation of the complexes in DMF. Hence the complexes can be regarded as non-electrolytes.

\subsection{Spectral studies of ligand and its complexes.}

The infrared spectral value of the ligand, and metal complexes, was represented in Table 2. The absorption wavenumber for a stretching vibration is directly proportional to force constant (bond strength) and inversely proportional to the mass of two atoms based on Hooke's law equation. From this relationship, it can be deduced that as the bond strength increases, the wavenumber increases. As the mass of one of the two atoms in the bond increases, the wavenumber decreases. As a result of this, it has been observed that the infrared spectrum of the ligand shows an important peak at $1554 \mathrm{~cm}^{-1}$, which can be assigned to $v(\mathrm{C}=\mathrm{N})$, respectively, in Figure 2. However, in the case of infrared spectra of complexes, the same peak $v(\mathrm{C}=\mathrm{N})$ has been shifted towards the lower wavelength region, indicating that the complexation had been taken place through the azomethine nitrogen group of the ligand. Further, the peaks of metal-oxygen (M-O) and metal-nitrogen (M-N) of the complexes are observed in the lower wavelength region in the range $509-530 \mathrm{~cm}^{-1}$, and $463-478 \mathrm{~cm}^{-1}$, which also proves that complexation has occurred through nitrogen and oxygen atom from the ligand $[9,10]$.

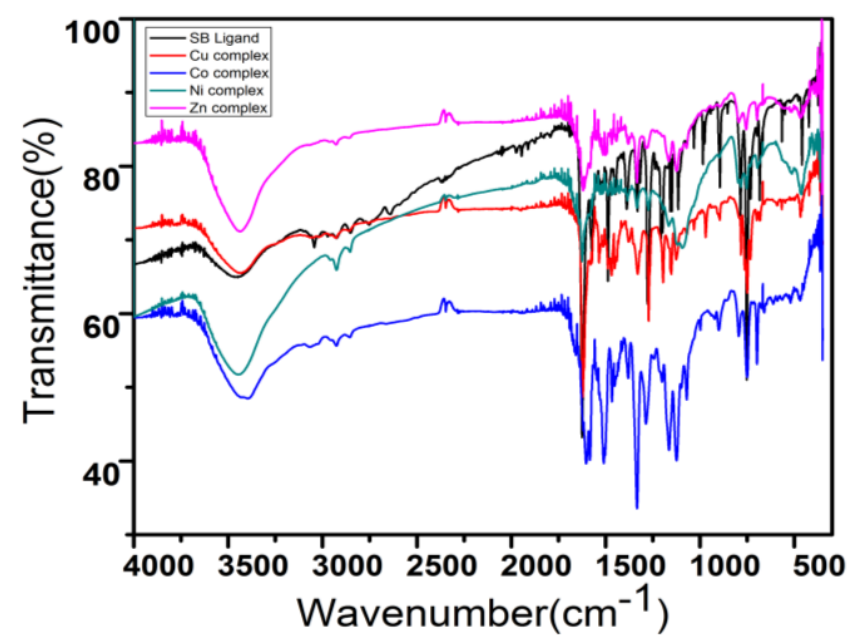

Figure 2. FT-IR spectra of (a) Schiff base ligand (black), (b) SB-Copper(II)complex (red), (c) SB-Cobalt (II) complex (blue), (d) SB-Nickel(II)complex (green), (e) SB-Zinc (II) complex (pink). 
Table 1. Elemental analytical data of Ligand and metal complexes.

\begin{tabular}{|c|c|c|c|c|c|c|c|}
\hline \multirow[t]{2}{*}{ SL.NO } & \multirow[t]{2}{*}{ Ligand/Complexes } & \multirow[t]{2}{*}{$\begin{array}{l}\text { Physical } \\
\text { appearance }\end{array}$} & \multicolumn{5}{|c|}{$\begin{array}{c}\text { Elemental analysis } \\
\text { Observed } \\
\text { (Calculated) }\end{array}$} \\
\hline & & & $\mathrm{C}$ & $\mathrm{H}$ & $\mathrm{N}$ & $\mathrm{S}$ & $\mathrm{M}($ metal) \\
\hline 1 & $\mathrm{C}_{21} \mathrm{H}_{16} \mathrm{~N}_{3} \mathrm{O}_{2} \mathrm{~F}_{3}$ & Yellow & $\begin{array}{c}64.64 \\
(63.15)\end{array}$ & $\begin{array}{c}4.04 \\
(4.03)\end{array}$ & $\begin{array}{c}10.55 \\
(10.52)\end{array}$ & $\begin{array}{l}- \\
-\end{array}$ & $\begin{array}{l}- \\
-\end{array}$ \\
\hline 2 & $\mathrm{C}_{21} \mathrm{H}_{20} \mathrm{CuN}_{3} \mathrm{O}_{4} \mathrm{~F}_{3}$ & Green & $\begin{array}{l}28.10 \\
(28.07)\end{array}$ & $\begin{array}{c}2.30 \\
(2.24)\end{array}$ & $\begin{array}{c}4.10 \\
(4.67)\end{array}$ & $\begin{array}{l}- \\
-\end{array}$ & $\begin{array}{c}7.10 \\
(7.07)\end{array}$ \\
\hline 3 & $\mathrm{C}_{21} \mathrm{H}_{20} \mathrm{CoN}_{3} \mathrm{O}_{4} \mathrm{~F}_{3}$ & Red & $\begin{array}{c}28.54 \\
(28.22)\end{array}$ & $\begin{array}{c}2.50 \\
(2.25)\end{array}$ & $\begin{array}{c}4.90 \\
(4.70)\end{array}$ & $\begin{array}{l}- \\
-\end{array}$ & $\begin{array}{c}7.02 \\
(6.59)\end{array}$ \\
\hline 4 & $\mathrm{C}_{21} \mathrm{H}_{20} \mathrm{NiN}_{3} \mathrm{O}_{4} \mathrm{~F}_{3}$ & Yellow & $\begin{array}{c}28.28 \\
(28.23) \\
\end{array}$ & $\begin{array}{c}2.30 \\
(2.25) \\
\end{array}$ & $\begin{array}{c}4.12 \\
(4.70) \\
\end{array}$ & $\begin{array}{l}- \\
- \\
\end{array}$ & $\begin{array}{c}6.72 \\
(6.56) \\
\end{array}$ \\
\hline 5 & $\mathrm{C}_{21} \mathrm{H}_{20} \mathrm{ZnN}_{3} \mathrm{O}_{4} \mathrm{~F}_{3}$ & Light Yellow & $\begin{array}{c}28.08 \\
(28.01)\end{array}$ & $\begin{array}{c}2.50 \\
(2.23)\end{array}$ & $\begin{array}{c}4.89 \\
(4.66)\end{array}$ & $\begin{array}{l}- \\
-\end{array}$ & $\begin{array}{c}7.32 \\
(7.26)\end{array}$ \\
\hline
\end{tabular}

Table 2. Selected infrared data of the ligand and SB-metal complexes.

\begin{tabular}{l|l|c|c|c|c}
\multirow{2}{*}{ SL.NO } & \multirow{2}{*}{ Compounds } & \multicolumn{4}{|c}{ Wavelength $\left(\mathbf{c m}^{-\mathbf{1}}\right)$} \\
\cline { 3 - 6 } & & $v(\mathrm{~N}-\mathrm{H})$ & $v(\mathrm{C}=\mathrm{N})$ & $v(\mathrm{M}-\mathrm{O})$ & $v(\mathrm{M}-\mathrm{N})$ \\
\hline $\mathbf{1}$ & $\mathrm{C}_{21} \mathrm{H}_{16} \mathrm{~N}_{3} \mathrm{O}_{2} \mathrm{~F}_{3}$ & 3050 & 1554 & - & - \\
\hline $\mathbf{2}$ & $\mathrm{C}_{21} \mathrm{H}_{20} \mathrm{CuN}_{3} \mathrm{O}_{4} \mathrm{~F}_{3}$ & 2930 & 1477 & 530 & 463 \\
\hline $\mathbf{3}$ & $\mathrm{C}_{21} \mathrm{H}_{20} \mathrm{CoN}_{3} \mathrm{O}_{4} \mathrm{~F}_{3}$ & 2930 & 1517 & 520 & 478 \\
\hline $\mathbf{4}$ & $\mathrm{C}_{21} \mathrm{H}_{20} \mathrm{NiN}_{3} \mathrm{O}_{4} \mathrm{~F}_{3}$ & 2910 & 1500 & 510 & 463 \\
\hline $\mathbf{5}$ & $\mathrm{C}_{21} \mathrm{H}_{20} \mathrm{ZnN}_{3} \mathrm{O}_{4} \mathrm{~F}_{3}$ & 2924 & 1500 & 509 & 463
\end{tabular}

\subsection{Electronic spectra and magnetic susceptibility.}

The electronic spectra of ligands and complexes are given in Table 3 and Figure 3 . The Schiff base ligands $\mathrm{HL}_{1}, \mathrm{HL}_{2}, \mathrm{HL}_{3}$, and $\mathrm{HL}_{4}$ all show two absorption bands ranging from 310 $400 \mathrm{~nm}$. These bands may be assigned due to ligand centered transitions (intra ligand) $\pi-\pi^{*}$ and $\mathrm{n}-\pi^{*}$ of benzene and non-bonding electrons present on the nitrogen atom of the azomethine group. The $\mathrm{Cu}(\mathrm{II})$ complex shows two absorption bands at 301 and $373 \mathrm{~nm}$; these may be assigned due to $\pi-\pi^{*}$ and ${ }^{2} \mathrm{~B}_{1 \mathrm{~g}} \rightarrow{ }^{2} \mathrm{E}_{\mathrm{g}}$ transitions.

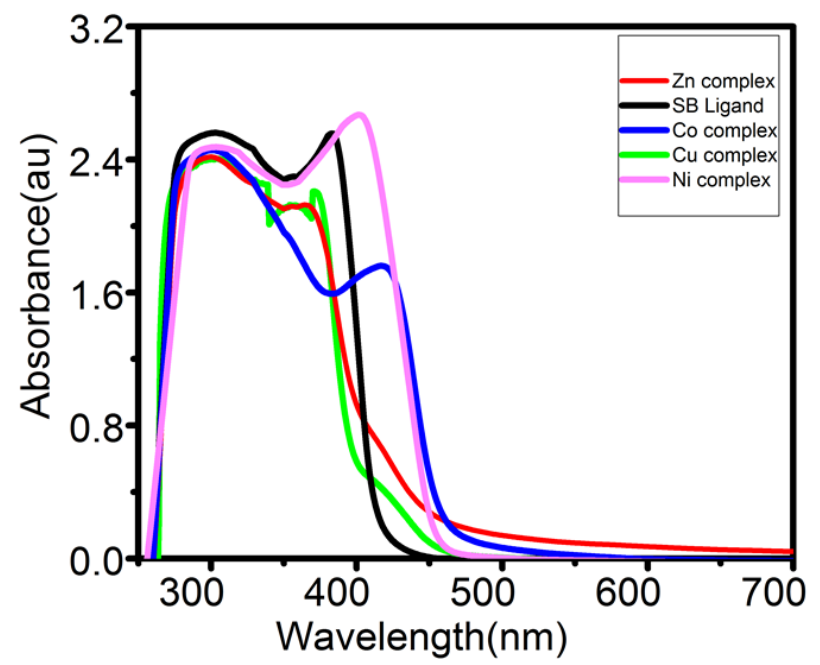

Figure 3. UV Spectrum of (a) Schiff base ligand (black), (b) SB-Copper (II) complex (green), (c) SB-Cobalt (II) complex (blue), (d) SB-Nickel (II) complex (pink), (e) SB-Zinc (II) complex (red).

These observations favor distorted octahedral geometry around $\mathrm{Cu}$ (II) complex. Further, the magnetic moment value for $\mathrm{Cu}$ (II) complex in the range of 1.90 B.M. (Bohr Magneton) also supports the distorted octahedral geometry [11]. The Co (II) complex exhibits two intense bands at 307 and $420 \mathrm{~nm}$, which may be assigned due to $\pi-\pi^{*}$ and $(\mathrm{F})^{4} \mathrm{~T}_{1 \mathrm{~g}} \rightarrow{ }^{4} \mathrm{~T}_{1 \mathrm{~g}}(\mathrm{P})$ transitions. These transitions indicate a high spin octahedral geometry for Co (II) complex. Also, the magnetic moment value 4.07 B.M. for Co (II) complex signifies its octahedral 
configuration. Two broad bands at 302 and $401 \mathrm{~nm}$ have been observed for Ni (II) complex; these bands may be assigned due to $\pi-\pi^{*}$ and ${ }^{3} \mathrm{~A}_{2 g}(\mathrm{~F}) \rightarrow{ }^{3} \mathrm{~T}_{1 \mathrm{~g}}(\mathrm{P})$ transitions, respectively [27]. This data suggests octahedral geometry for Ni (II) complex. The magnetic moment value 2.99 B.M. for Ni (II) complex suggests two unpaired electrons. Therefore, these values are in good agreement with those reported for the octahedral geometry of Ni (II) complexes. The Zn (II) complex shows only the charge transfer transitions at $297,363 \mathrm{~nm}$, which can be assigned due to charge transfer from ligand to metal or vice-versa. Since $\mathrm{Zn}$ (II) belongs to $\mathrm{d}^{10}$ configuration, no d-d transitions can be expected. Hence $\mathrm{Zn}$ (II) complex is diamagnetic; its magnetic properties could not be investigated. [12-15].

Table 3. Electronic spectral data of Schiff base ligands and metal complexes.

\begin{tabular}{c|c|c|c} 
SL.NO & Compounds & Absorption bands (nm) & Assigned Transitions \\
\hline $\mathbf{1}$ & $\mathrm{C}_{21} \mathrm{H}_{16} \mathrm{~N}_{3} \mathrm{O}_{2} \mathrm{~F}_{3}\left(\mathrm{HL}_{1}\right)$ & 303,383 & $\pi \rightarrow \pi^{*}, \mathrm{n} \rightarrow \pi^{*}$ \\
\hline $\mathbf{2}$ & $\mathrm{C}_{21} \mathrm{H}_{16} \mathrm{~N}_{3} \mathrm{O}_{2} \mathrm{~F}_{3} \mathrm{Cl}\left(\mathrm{HL}_{2}\right)$ & 338,400 & $\pi \rightarrow \pi^{*}, \mathrm{n} \rightarrow \pi^{*}$ \\
\hline $\mathbf{3}$ & $\left.\mathrm{C}_{21} \mathrm{H}_{16} \mathrm{~N}_{3} \mathrm{O}_{2} \mathrm{~F}_{3} \mathrm{Br}_{(\mathrm{HL}}\right)$ & 324,390 & $\pi \rightarrow \pi^{*}, \mathrm{n} \rightarrow \pi^{*}$ \\
\hline $\mathbf{4}$ & $\mathrm{C}_{21} \mathrm{H}_{16} \mathrm{~N}_{3} \mathrm{O}_{2} \mathrm{~F}_{3} \mathrm{CH}_{3}\left(\mathrm{HL}_{4}\right)$ & 328,396 & $\pi \rightarrow \pi^{*} \mathrm{n} \rightarrow \pi^{*}$ \\
\hline $\mathbf{5}$ & $\mathrm{C}_{21} \mathrm{H}_{20} \mathrm{CuN}_{3} \mathrm{O}_{4} \mathrm{~F}_{3}$ & 301,373 & $\pi \rightarrow \pi^{*}{ }^{2} \mathrm{~B}_{1 \mathrm{~g}} \rightarrow{ }^{2} \mathrm{E}_{\mathrm{g}}$ \\
\hline $\mathbf{6}$ & $\mathrm{C}_{21} \mathrm{H}_{20} \mathrm{CoN}_{3} \mathrm{O}_{4} \mathrm{~F}_{3}$ & 307,420 & $\pi \rightarrow \pi^{*},(\mathrm{~F})^{4} \mathrm{~T}_{1 \mathrm{~g}} \rightarrow{ }^{4} \mathrm{~T}_{1 \mathrm{~g}}(\mathrm{P})$ \\
\hline $\mathbf{8}$ & $\mathrm{C}_{21} \mathrm{H}_{20} \mathrm{NiN}_{3} \mathrm{O}_{4} \mathrm{~F}_{3}$ & 302,401 & $\pi \rightarrow \pi^{*},{ }^{3} \mathrm{~A}_{2 \mathrm{~g}}(\mathrm{~F}) \rightarrow{ }^{3} \mathrm{~T}_{1 \mathrm{~g}}(\mathrm{P})$ \\
\hline & $\mathrm{C}_{21} \mathrm{H}_{20} \mathrm{ZnN}_{3} \mathrm{O}_{4} \mathrm{~F}_{3}$ & 297,363 & $\pi \rightarrow \pi^{*}, \mathrm{n} \rightarrow \pi^{*}$
\end{tabular}

\section{3. ${ }^{1}$ HNMR spectra.}

The ${ }^{1} \mathrm{HNMR}$ spectrum of the Schiff base ligand is represented in Figure 4. The peak at $1.27 \mathrm{ppm}$ may be assigned due to $-\mathrm{NH}$ attached to the aromatic ring. The peaks between $6.95-$ $7.4 \mathrm{ppm}$ show the presence of aromatic protons. The free $-\mathrm{NH}$ appears at $8.71 \mathrm{ppm}$. The peak at $11.37 \mathrm{ppm}$ appears because of the phenolic $-\mathrm{OH}$ group.
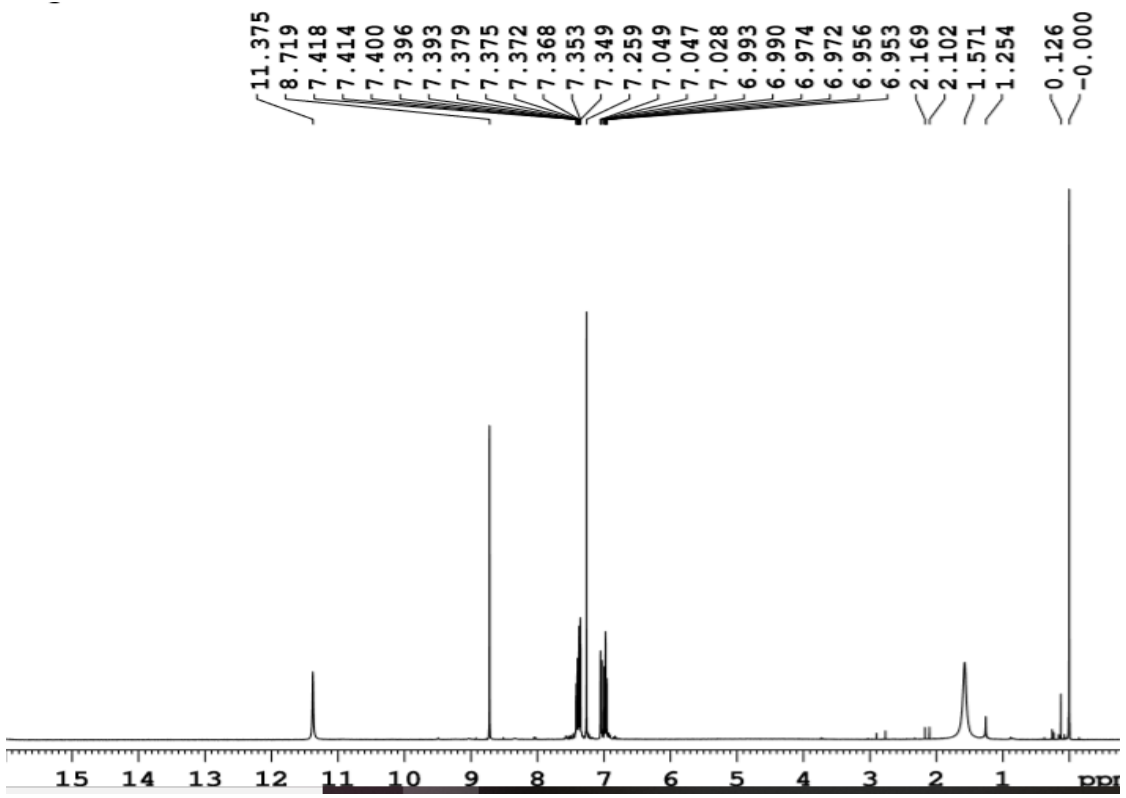

Figure 4. The ${ }^{1}$ HNMR spectrum of the Schiff base ligand.

\subsection{Mass spectra.}

The mass spectrum of the Schiff base ligand $\left(\mathrm{C}_{21} \mathrm{H}_{16} \mathrm{~N}_{3} \mathrm{O}_{2} \mathrm{~F}_{3}\right)$ Figure 5 shows a molecular ion peak, $\mathrm{M}^{+}$at $\mathrm{m} / \mathrm{z} 399.20$, which is in good agreement with the calculated molecular formula, i.e., 399.36The other $\mathrm{m} / \mathrm{z}$ peaks at 328, 240, 211, 188, 130 found may be 
due to fragmentations of $\mathrm{C}_{16} \mathrm{H}_{14} \mathrm{~F}_{3} \mathrm{~N}_{3} \mathrm{O}, \mathrm{C}_{13} \mathrm{H}_{10} \mathrm{~F}_{3} \mathrm{~N}, \mathrm{C}_{13} \mathrm{H}_{11} \mathrm{~F}_{2} \mathrm{~N}, \mathrm{C}_{13} \mathrm{H}_{13} \mathrm{~N}, \mathrm{C}_{9} \mathrm{H}_{11} \mathrm{~N}$ respectively [16].

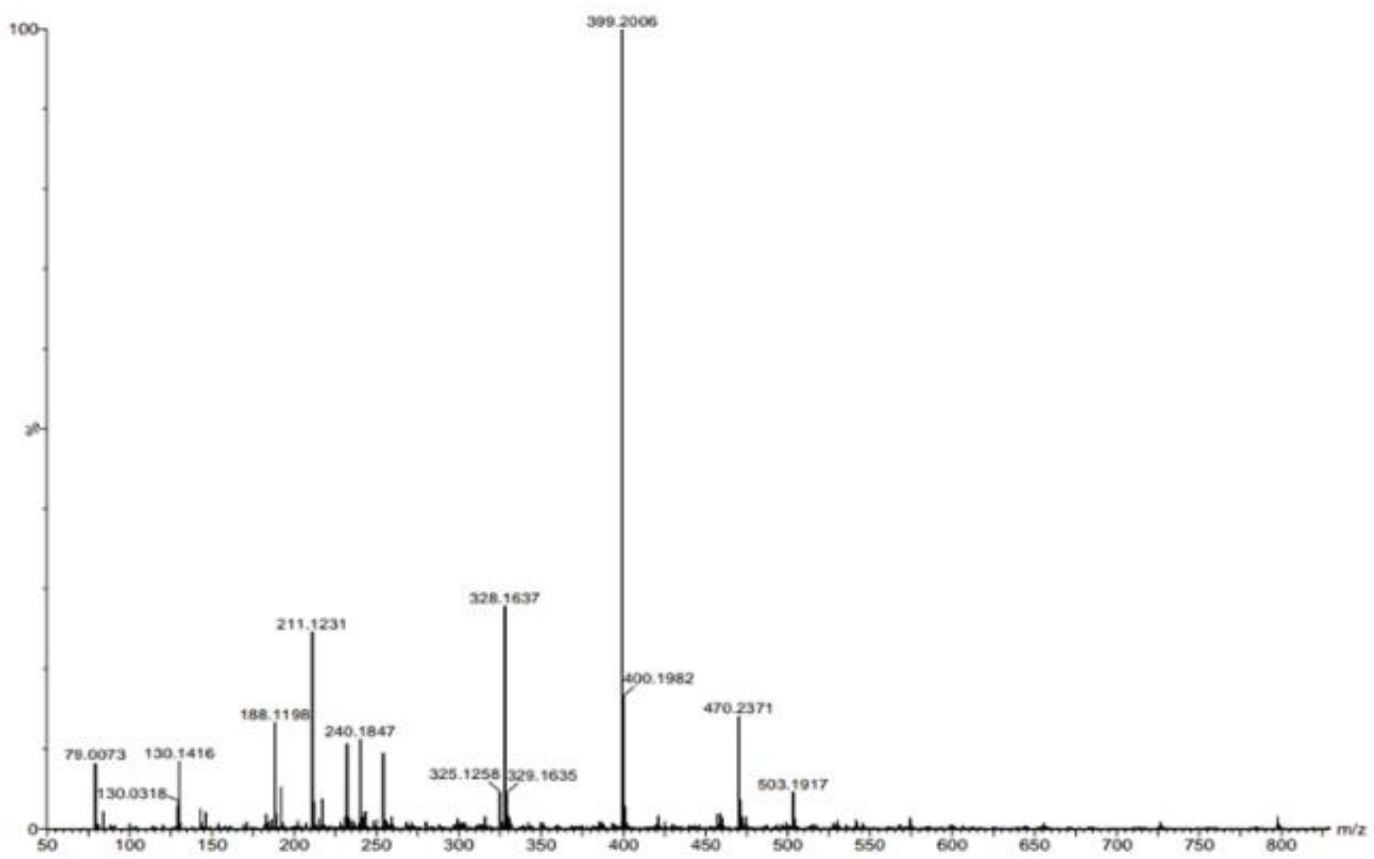

Figure 5. Mass spectrum of the Schiff base ligand.

\subsection{XRD spectra.}

Figure 6 shows the indexed XRD pattern of the prepared cobalt(II)complex, which shows Bragg's reflections due to the crystalline nature of the composite. The reflection in the pattern matches with some literature results in an excellent manner. Unit cell parameters were identified by least-square refinement of the XRD data. The presence of both Schiff base ligand and complex reflections in a single XRD pattern indicates the formation of Schiff base ligand combined with metal complex [28].

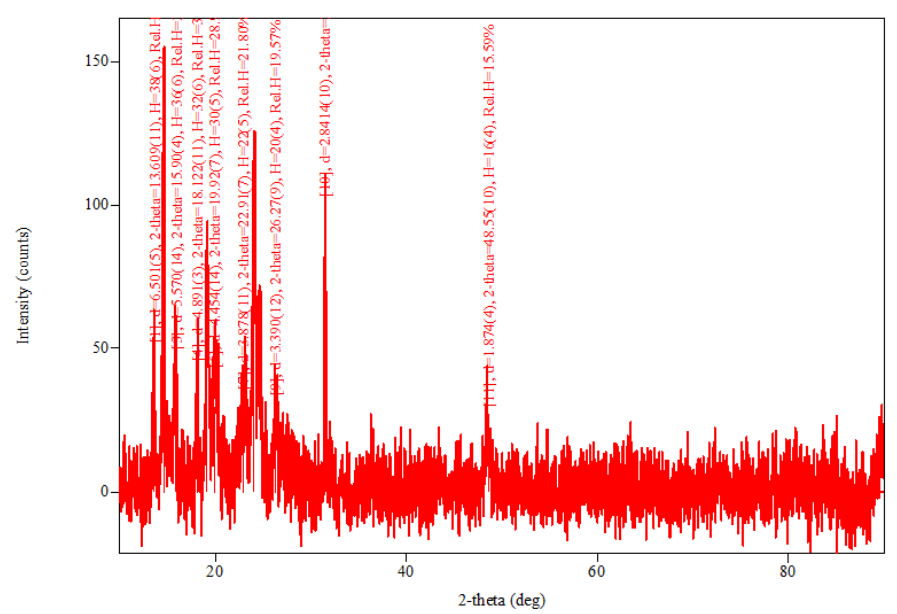

Figure 6. XRD pattern of cobalt (II) complex.

\subsection{Thermogravimetric analysis.}

Figure 7 demonstrates TGA thermogram of Schiff base ligand substituted with metal complex $\mathrm{Co}(\mathrm{II}), \mathrm{Cu}(\mathrm{II}), \mathrm{Ni}(\mathrm{II})$, and $\mathrm{Zn}$ (II). These traces give information about the percent weight loss of metal complex upon increasing the temperature, which indicates thermal stability, material purity, and moisture content of the composites. The thermogram indicates 
three-step mass misfortune with prevalent weight loss of metal complex samples. The primary mass misfortune from 10 to $100{ }^{\circ} \mathrm{C}$ is moderate and demonstrates loss of moisture and organic component from the substituted complex. This indicates the fast decay of the specimen that has occurred. The second step, while temperature increases from 100 to $250{ }^{\circ} \mathrm{C}$ indicates loss of organic molecules and metal complex is very stable up to 250 to $550{ }^{\circ} \mathrm{C}$; after this temperature, steeping had taken place due to decomposition of the metal complex [17, 18, 26].
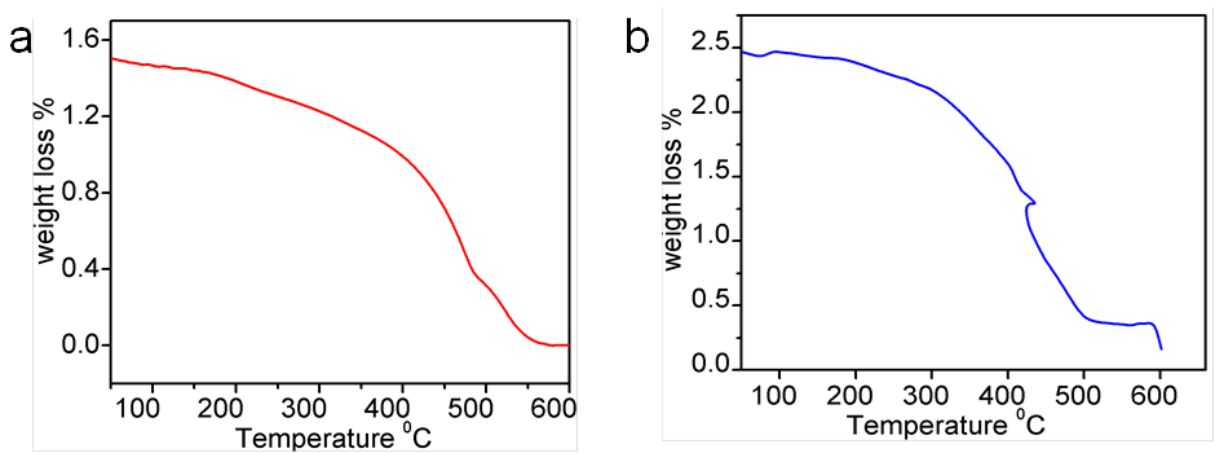

Figure 7. (a): TGA graph trace of (a) SB-Co (II) complex and (b) SB- Cu (II) complex.

3.6.1. Electrochemical study of modified electrode.

The electrochemical study of the modified electrodes was carried out in $\mathrm{pH} 7 \mathrm{PBS}$ and modified SB Cobalt (II) complex/GCE using CV techniques to determine the properties in synthesized SB Cobalt (II) complex oxidation behavior. Figure 8 (thick line) illustrates comparative current response results obtained with the bare GCE, and modified SBcomplex/GCE (inset Figure 8 doted curves), and the bare GCE showed no current response inset Figure 8 curves (thick curve). When GCE was modified with SB Co complex/GCE, the high ipa response was observed compared to bare GCE. The CV graph showed that the SB$\mathrm{Co}$ (II) complexes exhibited one oxidation peak, indicating that the synthesized Co (II) complex is electro-active.

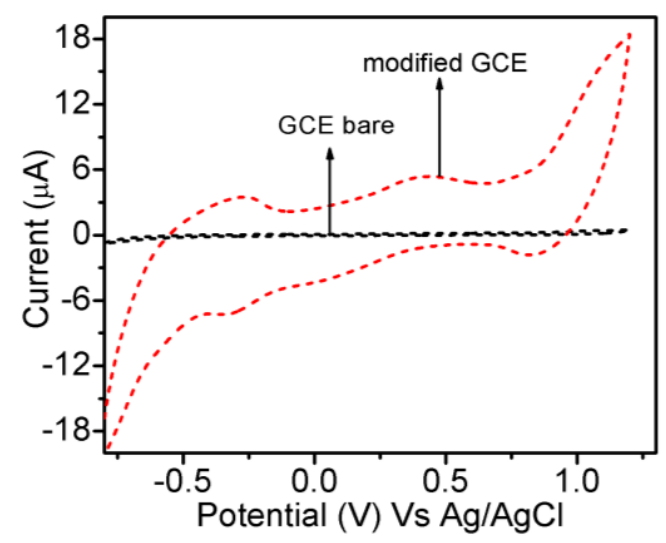

Figure 8. Cyclic voltammograms of a bare GCE (Thick line); (b) the Co(II) Complex modified glassy carbon electrode (dotted line) in buffer solution ( $\mathrm{pH} 7.0)$ and a scan rate of $50 \mathrm{mVs}^{-1}$.

\subsubsection{Electrochemical determination of uric acid.}

Figure 9 and Table 4 shows the oxidation of UA at the modified GCE. The results exhibited that UA compounds were oxidized with lower peak potentials. UA's oxidation peak potentials on the drop coated GCE displayed crystal clear peaks with $0.50 \mathrm{~V}$ vs. Ag/AgCl. In addition, peak potentials in the modified electrode had +ve potential shifts. These shifts in the 
oxidation peak potentials and increasing currents of the oxidation peak potential with drop coated electrodes indicate that the ingrained electrode on UA's oxidation plays a catalytic effect. The influence of the scan rate on the Ipa of uric acid was studied by CV. The results showed that the Ipa increased with increasing scan rate. Ipa and $v^{1 / 2}$ show a good linear relationship within a scan rate range of $10-100 \mathrm{mVs}^{-1}$ which confirms a modified electrode is a diffusion-controlled process $\left(r^{2}=0.993\right)$.
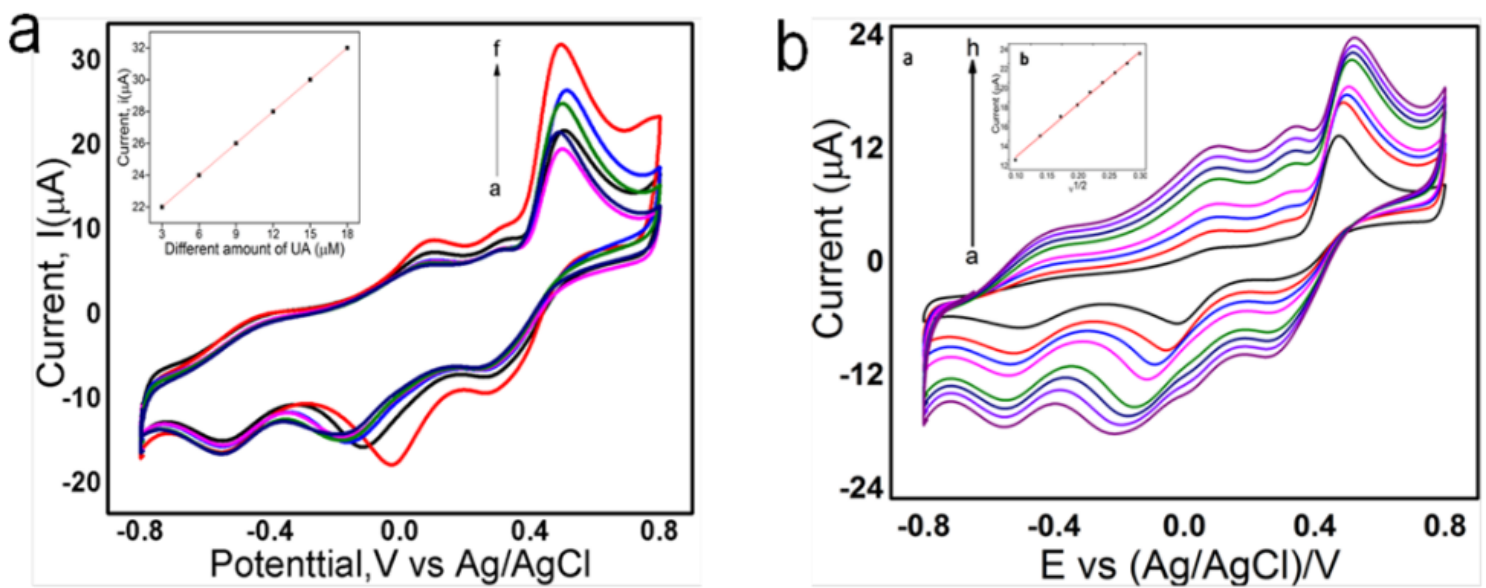

Figure 9. CV of SB-cobalt (II) complex modified GCE (a) modified GCE with different concentration 0.5 to 1.8 $\mu \mathrm{L}$ of UA in PBS ( $\mathrm{pH} 7.0$ ) inset the linearity graph shows concentration vs. peak current (b) different scan rate 10 to $100 \mathrm{mVs}^{-1}$ inset graph shows that $\mathrm{v}^{1 / 2} / \mathrm{Ipa}$.

Table 4. Performance of the proposed sensors with some modified electrodes used for the determination of uric

\begin{tabular}{|c|c|c|c|c|c|}
\hline Electrodes & Methods & $\begin{array}{l}\text { Linear range } \\
(\mu \mathrm{mol} / \mathrm{L})\end{array}$ & $\begin{array}{l}\text { Sensitivity } \\
\left(\mu \mathbf{A} \mu \mathbf{M}^{-1}\right)\end{array}$ & $\begin{array}{l}\text { LOD } \\
(\mu \mathrm{mol} / \mathrm{L})\end{array}$ & Ref. \\
\hline Uricase/HRP-cds & $\mathrm{CV}$ & $125-1000$ & - & 125 & 25 \\
\hline $\begin{array}{l}\text { DBCMAT-CoPc } \\
\text { /MWCNT/GCE }\end{array}$ & $\mathrm{CV}$ & $0.1-1.8$ & 131.85 & 0.03 & 06 \\
\hline RGO/GCE & $\mathrm{CA}$ & $02-600$ & - & 1.0 & 26 \\
\hline SB-Co(II)Complex/GCE & $\mathrm{CV}$ & $0.5-1.8$ & 128.46 & 0.16 & This work \\
\hline
\end{tabular}

\subsubsection{Stability studies.}

The stability of the fabricated sensors towards UA determination was investigated at 20 repeated CV scans in $\mathrm{pH} 7 \mathrm{PBS}$ containing $0.5 \mu \mathrm{M}$ of $\mathrm{UA}$ at a scan rate of $50 \mathrm{mV} \mathrm{s}^{-1}$. From the various scan runs, it was found that the Ip of the first scan was higher than the Ip of the second scan, and after the third scan, there were no changes in the current response. This behavior was observed with all the four modified GCE. Therefore the percentage current drop obtained was $4.75 \%$, SB-Co(II)complex/GCE modified electrode, respectively. Thus, the peak currents $\left(1^{\text {st }}\right.$ to $10^{\text {th }}$ cycles $)$ remained almost stable, indicating good electrode stability during repeated cycles. These results suggest some level of adsorption of UA at the surface of the modified electrode.

\subsubsection{Reproducibility and repeatability studies.}

The modified electrode of SB-Co(II)complex/GCE was constructed in five sets to determine the duplicability and, in turn, the analysis's accuracy. The detection of UA $(0.5 \mu \mathrm{M})$ was performed on the drop-coated SB-Co(II)complex/GC electrode by CV method. The RSD was calculated and found to be $3.1 \%$ for SB-Co(II)complex/GCE. The repeatability was performed using the modified electrode to detect UA $(0.5 \mu \mathrm{M})$ by taking five repeated $\mathrm{CV}$ 
measurements using the same SB-Co(II)complex/GCE. The fabricated electrodes endorse satisfactory reproducibility $(3.1 \%)$ and repeatability (RSD-1.6\%).

3.6.5. Anti-inflammatory activity.

The Schiff base ligand, $\mathrm{Cu}(\mathrm{II})$ complex, and $\mathrm{Zn}$ (II) complex were screened for antiinflammatory activity against Hyaluronidase, a mucolytic enzyme, in concentrations of $10 \mu \mathrm{g}$, $50 \mu \mathrm{g}$, and $100 \mu \mathrm{g}$, along with the standard drug Flufenamic acid. The results are represented in Figure 10. It has been observed that at a concentration of $10 \mu \mathrm{g}$, the ligand and $\mathrm{Zn}$ (II) complex show more activity than the standard drug. At concentrations of $50 \mu \mathrm{g}$ and $100 \mu \mathrm{g}$, the $\mathrm{Zn}$ (II) complex shows more activity than ligand. This comparative study indicates that metal complexes exhibit good biological activity than free ligand and standard drug [31]. The increase in metal complexes' biological activity is mainly because of metal ions' effect on the normal cell process. Such increased metal complexes' increased activity can be explained based on overtone's concept and chelation therapy [19, 20, 26].

\subsubsection{Antibacterial analysis.}

The drug, Schiff base ligand, and zinc complex, were tested for antibacterial activity using agar diffusion method against Pseudomonas aeruginosa bacteria. The sample solution was prepared by dissolving20mg in $1 \mathrm{ml}$ of DMSO. The media used was Peptone-10 g, NaCl$10 \mathrm{~g}$, and Yeast extract 5g, Agar $20 \mathrm{~g}$ in $1000 \mathrm{ml}$ of distilled water. Initially, bacteria's stock cultures were revived by inoculating in broth media and grown at $37^{\circ} \mathrm{C}$ for $18 \mathrm{hrs}$. The agar plates of the above media were prepared, and wells were made on the plate. Each plate was inoculated with $18 \mathrm{hrs}$ old cultures (100 $\mu \mathrm{l}, 10-4 \mathrm{CFU})$ and spread evenly on the plate. After 20 minutes, the wells were filled with the compound and different concentrations [32]. All the plates were incubated at $37{ }^{\circ} \mathrm{C}$ for $24 \mathrm{hrs}$, and the inhibition zone $(\mathrm{mm})$ diameter was noted. The concentrations screened were $31.25,62.5,125,250,500$, and $1000 \mu \mathrm{g}$. The results are represented in Table 5, followed by images (Figure 11). From Table 5, it is observed that the Schiff base ligand, the zinc complex showed good activity compared to the original drug Flufenamic acid. In contrast, they showed moderate activity compared to the standard drug Ciprofloxacin[21-25].

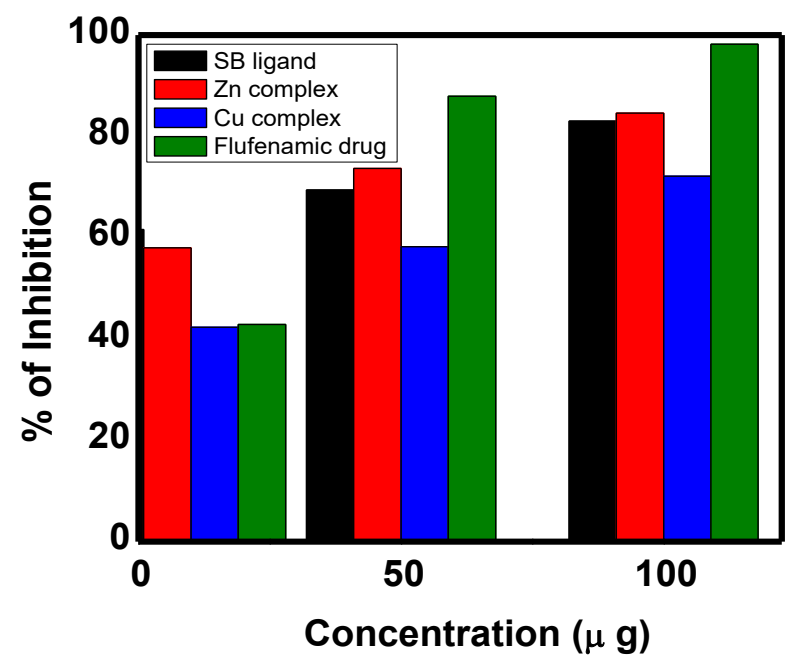

Figure 10. Anti-inflammatory activity of the drug, SB ligand and metal complexes against the enzyme Hyaluronidase 
Table 5. Antibacterial analysis against Pseudomonas aeruginosa bacteria.

\begin{tabular}{|c|c|c|c|c|c|c|c|}
\hline Sample & $31.25 \mu \mathrm{g}$ & $62.5 \mu \mathrm{g}$ & $125 \mu \mathrm{g}$ & $250 \mu \mathrm{g}$ & $500 \mu \mathrm{g}$ & $1000 \mu \mathrm{g}$ & MIC $\mu \mathrm{g}$ \\
\hline Flufenamic acid & 0 & 0 & 0 & 0 & 0 & 5 & 1000 \\
\hline Zn complex & 0 & 0 & 0 & 0 & 5 & 10 & 500 \\
\hline SB complex & 0 & 0 & 0 & 0 & 9 & 13 & 25 \\
\hline & $25 \mu \mathrm{g}$ & $50 \mu \mathrm{g}$ & $100 \mu \mathrm{g}$ & $250 \mu \mathrm{g}$ & $500 \mu \mathrm{g}$ & $1000 \mu \mathrm{g}$ & $\mathrm{MIC} \mu \mathrm{g}$ \\
\hline Ciprofloxacin & 25 & 28 & 32 & 34 & 36 & * & 25 \\
\hline
\end{tabular}

(a)

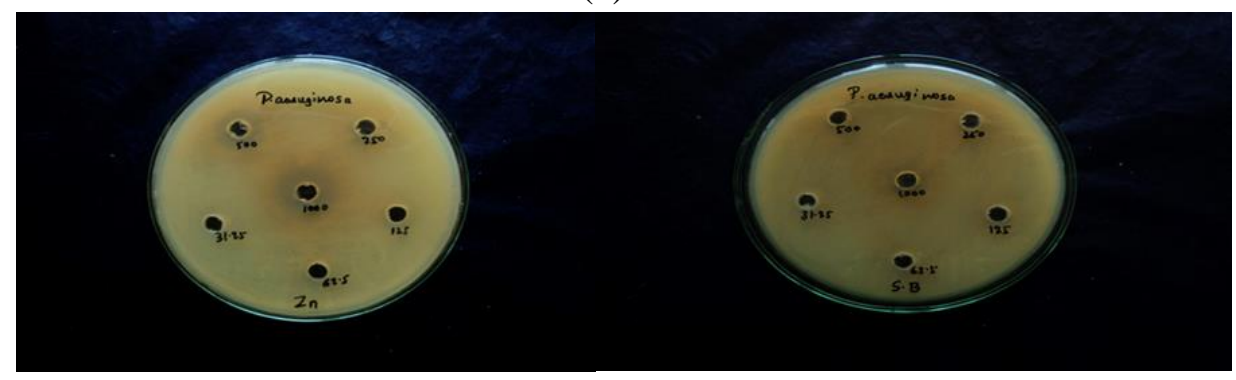

(b)

(c)

Figure 11. Antibacterial tests for (a) Flufenamic Acid Drug, (b) Zn complex, and (c) SB ligand.

\section{Conclusions}

Research has shown significant progress in the utilization of metal-based drugs in medical diagnosis. In the present work, Schiff base metal complexes of $\mathrm{Cu}(\mathrm{II}), \mathrm{Co}(\mathrm{II}), \mathrm{Ni}(\mathrm{II})$, and $\mathrm{Zn}(\mathrm{II})$ have been synthesized and characterized by various spectral and electrochemical analysis. The spectral studies reveal that the metal complexes exhibit octahedral geometry. Further studies indicate that SB-Co(II)complex/GCE exhibit electrochemical sensing oxidation of UA. The fabricated electrode has many advantages, such as easy preparation, enhanced electro-catalytic activity, very good sensitivity, and LOD valves. The comparative antiinflammatory studies showed that metal complexes exhibited good activity than the free ligand and the standard drug. The antibacterial analysis proves that the SB ligand and synthesized complex show higher activity than the original drug.

\section{Funding}

This research received no external funding.

\section{Acknowledgments}

One of the authors K.G. Shilpa, thanks Vijayanagara Sri Krishnadevaraya University for the fellowship under SC/ST scheme, and also thanks VGST, GRD-229 Government of Karnataka CISEE Project for providing cyclic voltammetry (CV)instrument. 


\section{Conflicts of Interest}

\section{The authors declare no conflict of interest.}

\section{References}

1. da Silva, C.M.; da Silva, D.L.; Modolo, L.V.; Alves, R.B.; de Resende, M.A.; Martins, C.V.B.; de Fátima, $\hat{A}$. Schiff bases: A short review of their antimicrobial activities. Journal of Advanced Research 2011, 2, 18, https://doi.org/10.1016/j.jare.2010.05.004.

2. Tarushi, A.; Kastanias, F.; Psycharis, V.; Raptopoulou, C.P.; Psomas, G.; Kessissoglou, D.P. A [24-MC-6] Zinc Metallacoronate with a Nonsteroidal Antiinflammatory Drug as the Constructing Ligand. Inorganic Chemistry 2012, 51, 7460-7462, https://doi.org/10.1021/ic3010757.

3. Dutt, V.V.S.E.; Mottola, H.A. Determination of uric acid at the microgram level by a kinetic procedure based on a pseudo-induction period. Analytical Chemistry 1974, 46, 17771781,https://doi.org/10.1021/ac60348a041.

4. Li, Y.; Lin, X. Simultaneous electroanalysis of dopamine, ascorbic acid and uric acid by poly (vinyl alcohol) covalently modified glassy carbon electrode. Sensors and Actuators B: Chemical 2006, 115, 134-139, https://doi.org/10.1016/j.snb.2005.08.022.

5. Jin, G.; Zhang, Y.; Cheng, W. Poly(p-aminobenzene sulfonic acid)-modified glassy carbon electrode for simultaneous detection of dopamine and ascorbic acid. Sensors and Actuators B: Chemical 2005, 107, 528534,https://doi.org/10.1016/j.snb.2004.11.018.

6. Pari, M.; Ramareddy, K.; Reddy, V. Electrochemical Investigation of Uric Acid using MWCNTs-Decorated Novel Substituted Cobalt(II) Phthalocyanine Modified GCE. Analytical and Bioanalytical Electrochemistry 2020, 11, 1383-1397.

7. Bundgaard, H.; Mørk, N.; Hoelgaard, A. Enhanced delivery of nalidixic acid through human skin via acyloxymethyl ester prodrugs. International Journal of Pharmaceutics 1989, 55, 91-97, https://doi.org/10.1016/0378-5173(89)90028-8.

8. Malik, S.; Ghosh, S.; Jain, B.; Singh, A.; Bhattacharya, M. Synthesis, Characterization, and Biological Evaluation of Some 3d-Metal Complexes of Schiff Base Derived from Xipamide Drug. International Journal of Inorganic Chemistry 2013, 2013.

9. Bharti, N.; Shailendra; Sharma, S.; Naqvi, F.; Azam, A. New palladium(II) complexes of 5-nitrothiophene2-carboxaldehyde thiosemicarbazones: synthesis, spectral studies and In vitro anti-Amoebic activity. Bioorganic \& Medicinal Chemistry 2003, 11, 2923-2929, https://doi.org/10.1016/S0968-0896(03)00213-X.

10. Kovala-Demertzi, D.; Yadav, P.N.; Demertzis, M.A.; Coluccia, M. Synthesis, crystal structure, spectral properties and cytotoxic activity of platinum(II) complexes of 2-acetyl pyridine and pyridine-2-carbaldehyde N(4)-ethyl-thiosemicarbazones. Journal of Inorganic Biochemistry 2000, 78, 347-354, https://doi.org/10.1016/s0162-0134(00)00063-5.

11. Dey, D.; Kaur, G.; Ranjani, A.; Gayathri, L.; Chakraborty, P.; Adhikary, J.; Pasan, J.; Dhanasekaran, D.; Choudhury, A.R.; Akbarsha, M.A.; Kole, N.; Biswas, B. A Trinuclear Zinc-Schiff Base Complex: Biocatalytic Activity and Cytotoxicity. European Journal of Inorganic Chemistry 2014, 2014, 3350-3358.

12. Tulu, M.; Mohammed Yimer, A. Catalytic Studies on Schiff Base Complexes of Co(II) and Ni(II) Using Benzoylation of Phenol. Modern Chemistry \& Applications 2018, 6, 1-6,https://doi.org/10.4172/23296798.1000260.

13. Kabeer, H.; Hanif, S.; Arsalan, A.; Asmat, S.; Younus, H.; Shakir, M. Structural-Dependent N,O-Donor Imine-Appended $\mathrm{Cu}(\mathrm{II}) / \mathrm{Zn}(\mathrm{II})$ Complexes: Synthesis, Spectral, and in Vitro Pharmacological Assessment. ACS Omega 2020, 5, 1229-1245,https://doi.org/10.1021/acsomega.9b03762.

14. Shit, S.; Rosair, G.; Mitra, S. A new tetranuclear copper(II) Schiff base complex containing Cu4O4 cubane core: Structural and spectral characterizations. Journal of Molecular Structure 2011, 991, 79-83, https://doi.org/10.1016/j.molstruc.2011.02.003.

15. Ebrahimi, H.P.; Hadi, J.S.; Abdulnabi, Z.A.; Bolandnazar, Z. Spectroscopic, thermal analysis and DFT computational studies of salen-type Schiff base complexes. Spectrochimica Acta Part A: Molecular and Biomolecular Spectroscopy 2014, 117, 485-492, https://doi.org/10.1016/j.saa.2013.08.044.

16. Sherif, O.E.; Abdel-Kader, N.S. DFT calculations, spectroscopic studies, thermal analysis and biological activity of supramolecular Schiff base complexes. Arabian Journal of Chemistry 2018, 11, 700-713, https://doi.org/10.1016/j.arabjc.2015.07.008

17. Pari, M.; Venugopala, K.; Nayaka, M. Synthesis, Spectral and Electrochemical Investigation of Azo-Bridged Metallophthalocyanine Polymer. Anal. Bioanal. Electrochem.2019,11, 460-483.

18. Pari, M.; Reddy, K.R.V. A Facile Cobalt (II) Tetra Amino Phthalocyanine Ingrained Poloy Aniline (PANI) Nano-fiber Film Layer Based Electrode Material for Amperometric Determination of Thiocyanate. Journal of Inorganic and Organometallic Polymers and Materials 2020, 30, 35113520,https://doi.org/10.1007/s10904-020-01515-8.

19. Leung, C.-H.; Lin, S.; Zhong, H.-J.; Ma, D.-L. Metal complexes as potential modulators of inflammatory and autoimmune responses. Chemical Science 2015, 6, 871-884,https://doi.org/10.1039/c4sc03094j. 
20. Kendur, U.; Chimmalagi, G.H.; Patil, S.M.; Gudasi, K.B.; Frampton, C.S.; Mangannavar, C.V.; Muchchandi, I.S. Mononuclear late first row transition metal complexes of ONO donor hydrazone ligand: Synthesis, characterization, crystallographic insight, in vivo and in vitro anti-inflammatory activity. Journal of Molecular Structure 2018, 1153, 299-310,https://doi.org/10.1016/j.molstruc.2017.10.022.

21. Ommenya, F.K.; Nyawade, E.A.; Andala, D.M.; Kinyua, J. Synthesis, Characterization and Antibacterial Activity of Schiff Base, 4-Chloro-2-\{(E)-[(4-Fluorophenyl)imino]methyl $\}$ phenol Metal (II) Complexes. Journal of Chemistry 2020, 2020, 1-8, https://doi.org/10.1155/2020/1745236.

22. Threlfall, E.J.; Fisher, I.S.T.; Ward, L.; Tschape;Gerner, S. Harmonization of Antibiotic Susceptibility Testing for Salmonella: Results of a Study by 18 National Reference Laboratories within the European Union-Funded Enter-Net Group. Microbial Drug Resistance1999, 5, 195-199, https://doi.org/10.1089/mdr.1999.5.195.

23. Arunkumar, L.; Sangappa, G.K.; Preeti, R.K.; Shashidhar, R. Green Synthesis, Characterization and Antibacterial Study of Ag-AuBimetallicNanocomposite using Tea Powder Extract. Biointerface Research in Applied Chemistry 2021, 11, 8087-8095, https://doi.org/10.33263/BRIAC111.80878095.

24. Divya, G.; Dharam, P.P.; Garima, K.; Rubina B. A Compressive Review on Synthesis and Biological Activity of Schiff Bases, International Research.Journal of Pharmacy 2019, 10, 18,https://doi.org/10.7897/2230-8407.1005153.

25. Parasuraman, B.; Rajendran, J.; Rajavel, R. An Insight into Antibacterial and Anticancer Activity of Homo and Hetero Binuclear Schiff Base Complexes. Oriental Journal of Chemistry 2017, 33, 12231234,http://dx.doi.org/10.13005/ojc/330321.

26. Nazirkar, B.; Mandewale, M.; Yamgar, R. Synthesis, characterization and antibacterial activity of Cu (II) and $\mathrm{Zn}$ (II) complexes of 5-aminobenzofuran-2-carboxylate Schiff base ligands. Journal of Taibah University for Science 2019, 13, 440-449, https://doi.org/10.1080/16583655.2019.1592316.

27. Lagashetty, A.; Ganiger, S.K.; Shashidhar. Synthesis, characterization and antibacterial study of Ag-Au Bimetallic nanocomposite by bioreduction using piper betle leaf extract. Heliyon 2019, 5, https://doi.org/10.1016/j.heliyon.2019.e02794.

28. Lagashetty, A.; Ganiger, S.K.; Preeti, R.K.; Reddy, S.; Pari, M. Microwave-assisted green synthesis, characterization and adsorption studies on metal oxide nanoparticles synthesized using Ficus Benghalensis plant leaf extracts. New Journal of Chemistry 2020, 44, 14095-14102, https://doi.org/10.1039/D0NJ01759K.

29. Sunil Kumar, N.; Krishnamurthy, G.; somegowda, M.; Pari, M.; Ravikumar Naik, T.R.; Jithedra Kumara, K.S.; Naik, S.; Kandagalla, S.; Naik, N. Synthesis, characterization, electrochemistry, biological and molecular docking studies of the novel $\mathrm{Co}(\mathrm{II}), \mathrm{Ni}(\mathrm{II})$ and $\mathrm{Cu}(\mathrm{II})$ complexes derived from methanethiol bridged (2-((1H-benzo[d]imidazol-2-yl)methylthio)-1H-benzo[d]imidazol-6-yl)(phenyl)methanone. Journal of Molecular Structure 2020, 1220, https://doi.org/10.1016/j.molstruc.2020.128586,

30. Zehra, S.; Roisnel, T.; Arjmand, F. Enantiomeric Amino Acid Schiff Base Copper(II) Complexes as a New Class of RNA-Targeted Metallo-Intercalators: Single X-ray Crystal Structural Details, Comparative in Vitro DNA/RNA Binding Profile, Cleavage, and Cytotoxicity. ACS Omega 2019, 4, 7691-7705, https://doi.org/10.1021/acsomega.9b00131.

31. Subhanandaraj, T.T.; Raghavan, K.T.; Narayanan, R. Antibacterial and antibiofilm activity of probiotic based silver nanoparticles is a green approach in biomedical applications. Letters in Applied NanoBioScience 2020, 9, 988-994, https://doi.org/10.33263/LIANBS92.988994.

32. Priya, A.; Saminathan, S.; Balasundaram, J. Green synthesis of NiO nanoparticles using Leucas Aspera and its antibacterial activity. Letters in Applied NanoBioScience 2020, 9, 1033-1036, https://doi.org/10.33263/LIANBS92.10331036. 